\title{
Video-assisted thoracoscopic lobectomy is associated with greater recurrence-free survival than stereotactic body radiotherapy for clinical stage I lung cancer
}

\author{
Lorraine D. Cornwell, MD, ${ }^{\mathrm{a}, \mathrm{b}}$ Alfredo E. Echeverria, MD, ${ }^{\mathrm{a}, \mathrm{b}}$ Jason Samuelian, DO, ${ }^{\mathrm{c}}$ Jessica Mayor, MD, ${ }^{\mathrm{a}, \mathrm{b}}$ \\ Roberto F. Casal, MD, ${ }^{\mathrm{a}, \mathrm{b}}$ Faisal G. Bakaeen, MD, ${ }^{\mathrm{d}, \mathrm{e}}$ Shuab Omer, MD, ${ }^{\mathrm{a}, \mathrm{b}}$ Ourania Preventza, MD, \\ Weiyuan Mai, MD, ${ }^{\mathrm{a}, \mathrm{b}}$ George Chen, MD, ${ }^{\mathrm{a}, \mathrm{b}}$ Katherine H. Simpson, MS, ${ }^{\mathrm{a}}$ Drew Moghanaki, MD, ${ }^{\mathrm{f}}$ and \\ Angela W. Zhu, MD ${ }^{\mathrm{a}, \mathrm{b}}$
}

\section{ABSTRACT}

Objective: Stereotactic body radiotherapy is the standard treatment for medically inoperable early-stage non-small cell lung cancer. Recent data suggest that in operable patients, stereotactic body radiotherapy produces outcomes comparable to those of surgical resection. In veterans with early non-small cell lung cancer, we compared the outcomes of stereotactic body radiotherapy and video-assisted thoracoscopic lobectomy.

Methods: We retrospectively reviewed data from 183 patients $(94.0 \%$ male) with clinical stage I non-small cell lung cancer who underwent stereotactic body radiotherapy $(\mathrm{n}=56)$ or video-assisted thoracoscopic lobectomy $(\mathrm{n}=127)$ from 2009 to 2014. Propensity matching was used to produce more comparable groups. Primary end points were tumor control and overall, recurrence-free, and lung-cancer-specific survival, as estimated by Kaplan-Meier actuarial analysis. Multivariable analysis was used to identify independent predictors.

Results: In the overall cohort, the patients who received stereotactic body radiotherapy were older than the patients who received video-assisted thoracoscopic lobectomy (median age, 79.5 vs 64 years) and had more comorbidities. In the 37 propensity-matched pairs, the 3-year actuarial tumor control rate was $54.3 \%$ after stereotactic body radiotherapy and $90.6 \%$ after video-assisted thoracoscopic lobectomy $(P=.0038)$. Actuarial lung cancer-specific 3-year survival was $78.1 \%$ (stereotactic body radiotherapy) versus $93.6 \%$ (video-assisted thoracoscopic lobectomy) $(P=.055)$. One-year overall, 3-year overall, and 3-year recurrence-free survivals were $89.2 \%, 52.9 \%$, and $38.5 \%$ after stereotactic body radiotherapy and $94.6 \%, 85.7 \%$, and $82.8 \%$ after video-assisted thoracoscopic lobectomy $(P<.005$ for all), respectively. In multivariable analysis, stereotactic body radiotherapy independently predicted recurrence and poorer survival.

Conclusions: In veteran patients with early-stage non-small cell lung cancer, video-assisted thoracoscopic lobectomy resulted in better disease control and survival than stereotactic body radiotherapy. Although prior reports suggest that stereotactic body radiotherapy is a suitable alternative to surgery in early-stage lung cancer, a prospective randomized trial is needed. Nevertheless, stereotactic body radiotherapy remains a suitable option for medically inoperable patients. (J Thorac Cardiovasc Surg 2018;155:395-402)

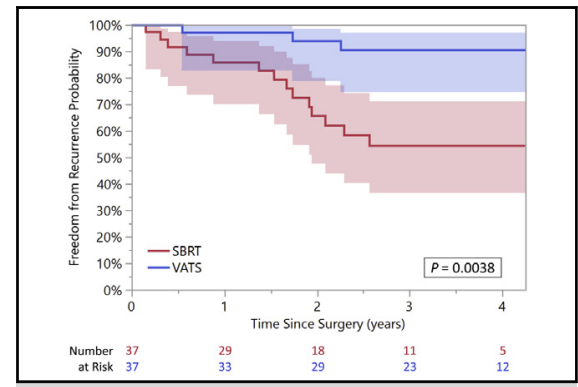

Freedom from recurrence after SBRT versus VATS Iobectomy in veterans with stage I lung cancer.

\section{Central Message}

In patients with early NSCLC, VATS is associated with better disease control and survival than SBRT.

\section{Perspective}

Recent data suggest that in operable patients with early-stage non-small cell lung cancer, SBRT is a valid alternative to surgical resection. However, in our propensity-matched patients, VATS was associated with better disease control and survival than SBRT. Nevertheless, SBRT remains a suitable option for medically inoperable patients.

See Editorial Commentary page 403.

See Editorial page 365 .

\footnotetext{
From the ${ }^{\mathrm{a}}$ Michael E. DeBakey VA Medical Center; ${ }^{\mathrm{b}}$ Baylor College of Medicine; ${ }^{\mathrm{e}}$ Texas Heart Institute, Houston, Tex; ${ }^{\mathrm{c}}$ Arizona Center for Cancer Care, Surprise, Ariz; ${ }^{\mathrm{d} C l e v e l a n d}$ Clinic, Cleveland, Ohio; and ${ }^{\mathrm{f}}$ The Hunter Holmes McGuire VA Medical Center, Richmond, Va.

Read at the 2016 Annual Meeting of the Association of VA Surgeons, Virginia Beach, Virginia, April 10-12, 2016.

Received for publication Jan 20, 2017; revisions received July 5, 2017; accepted for publication July 17, 2017; available ahead of print Sept 7, 2017.
}

\footnotetext{
Address for reprints: Lorraine D. Cornwell, MD, Division of Cardiothoracic Surgery, Department of Surgery, Michael E. DeBakey VAMC, OCL 112, 2002 Holcombe Blvd, Houston, TX 77030 (E-mail: cornwell@bcm.edu). 0022-5223/\$0.00

Published by Elsevier Inc. on behalf of The American Association for Thoracic Surgery

http://dx.doi.org/10.1016/j.jtcvs.2017.07.065
} 


\section{Abbreviations and Acronyms \\ $\mathrm{CCI}=$ Charlson Comorbidity Index \\ COPD $=$ chronic obstructive pulmonary disease \\ $\mathrm{CT}=$ computed tomography \\ $\mathrm{FEV}_{1}=$ forced expiratory volume in 1 second \\ NSCLC $=$ non-small cell lung cancer \\ $\mathrm{OR}=$ odds ratio \\ SBRT = stereotactic body radiotherapy \\ VATS = video-assisted thoracoscopic lobectomy}

Scanning this QR code will take you to the article title page.

Stereotactic body radiotherapy (SBRT) has emerged as an alternative to surgical resection for stage I non-small cell lung cancer (NSCLC). Currently, SBRT is the preferred treatment for patients who are deemed medically inoperable, providing better local control than traditional radiation therapy. ${ }^{1}$ Growing evidence supports the feasibility, safety, and efficacy of stereotactic radiotherapy, ${ }^{2-7}$ describing locoregional control rates of approximately $90 \%$ among patients who receive a biological equivalent dose of $100 \mathrm{~Gy}^{8}$ or more and 3-year cancer-specific survival approaching $90 \%$ for patients with stage I disease. ${ }^{9,10}$ Recently, the use of SBRT to treat early-stage lung cancer has rapidly increased, and patients are sometimes choosing SBRT over surgery to avoid invasive treatment. ${ }^{11-13}$

Studies comparing SBRT with surgical resection have produced conflicting results. Most studies are retrospective and thus have innate selection bias, and they often include many inoperable patients. ${ }^{14}$ Despite attempts at systematic review and meta-analysis, residual confounding still affects the comparisons made. ${ }^{15-17}$ Traditional results of surgery show 5-year cure rates of $60 \%$ to $80 \%$ for stage I lung cancer. SBRT has not been shown to produce comparable outcomes. ${ }^{18-20}$

Although the data demonstrate potential for equipoise to justify enrolling operable patients in randomized controlled trials of SBRT versus surgical resection, several such trials failed to accrue study patients. ${ }^{15}$ Nevertheless, in an analysis of the combined results of 2 unfinished trials (STARS and ROSEL), the authors concluded that SBRT "could be an option for treating operable stage I NSCLC." ${ }^{21}$ Extensive discourse in the literature highlights the limitations of this combined analysis: Many of the patients received open thoracotomy instead of video-assisted thoracoscopic lobectomy (VATS), and the small sample $(\mathrm{n}=58)$ did not give the analysis sufficient power to support any practice-changing recommendations..$^{22,23}$
Further comparisons of SBRT with surgery are needed. The results of SBRT have not been reported in the veteran population, who have high rates of smoking and comorbidities, such as chronic obstructive pulmonary disease (COPD) ${ }^{24}$ In addition, few studies have examined SBRT outcomes in a "real-world" setting with a contemporary surgical comparison group from the same high-risk population. ${ }^{25}$ We compared our recent results of SBRT with those of modern surgical VATS in veteran patients, using propensity matching in an attempt to create comparable groups.

\section{MATERIALS AND METHODS}

We queried a prospectively maintained thoracic database for patients with biopsy-proven, clinical stage I (T1-2, N0, M0) NSCLC treated with SBRT or VATS at our institution between July 1, 2009, and December 31, 2014. All patients underwent a positron emission tomography/computed tomography (CT) scan for staging. All cases were confirmed to be clinical stage I and had been discussed by a multidisciplinary tumor board. We excluded patients who had other malignancy within 5 years before treatment $(n=14)$, had inadequate follow-up $(n=4)$, or underwent any procedure more or less extensive than lobectomy $(n=14)$. Because of significant differences between the groups, we also excluded patients who were oxygen dependent $(\mathrm{n}=20$, all in SBRT group) or had central tumors ( $\mathrm{n}=15$, all in the VATS group). Central tumors were not treated with SBRT during this time period. The database was queried to obtain demographics, preprocedure clinical factors (including comorbidities), procedural details, and postprocedure outcomes. Ageadjusted Charlson Comorbidity Index (CCI) scores were used to estimate the severity of comorbidities. Surgical complications were graded by using Dindo and colleagues' classification, ${ }^{26}$ and the toxicity of SBRT was classified according to version 4.03 of the Common Terminology Criteria for Adverse Events. ${ }^{27}$ Our institutional review board approved the study.

\section{Stereotactic Body Radiotherapy Details}

Pretreatment gold fiducial markers were used in all patients and were placed by transthoracic CT-guided needle delivery or bronchoscopic means. Standard pretreatment workup included invasive mediastinal staging when feasible, with hilar and mediastinal lymph node sampling by endobronchial ultrasonography-guided transbronchial needle aspiration to evaluate for subclinical nodal metastases.

A complete thoracic helical CT was obtained at least 1 week after fiducial placement to delineate tumor and normal tissues. The gross tumor volume included the tumor visible on CT lung windows. There were no margin expansions to account for presumed microscopic disease, nor internal target volume to account for tumor motion, because real-time tumor tracking was used during each treatment. A uniform 5-mm expansion was used to create a planning target volume. Normal tissues at risk were contoured, including heart, esophagus, ipsilateral and contralateral lung, spinal cord, ribs, and chest wall.

In all cases, SBRT was delivered with noncoplanar beams by using the CyberKnife robotic delivery system (Accuray Inc, Sunnyvale, Calif) with $6 \mathrm{MV}$ photons and cone collimation. Image guidance was accomplished with fiducial marker tracking and a Synchrony (Accuray Inc) respiratory tracking system for real-time intra-fraction tumor motion tracking. Prophylactic dexamethasone $(4 \mathrm{mg}$ ) was administered orally approximately $30 \mathrm{mi}-$ nutes before each fraction. Treatment was delivered once daily on consecutive days. Doses and fractionation regimens were chosen by the treating radiation oncologists. The SBRT was delivered in 4 or 5 fractions, and dose was prescribed to the planning target volume.

\section{Surgery Details}

All surgical resections consisted of VATS with hilar and mediastinal lymph node dissection, by one surgeon (L.D.C.). The VATS operation 
generally involved a 3-incision approach, with a less than 5-cm access incision and full dissection and individual division of hilar structures. There were no conversions to open surgery.

\section{Follow-up}

After treatment, patients who received SBRT underwent clinical assessment and chest CT scanning every 3 months for the first year and then every 6 months thereafter. All patients were evaluated with a whole fluorodeoxyglucose-labeled positron emission tomography/CT scan 3 to 6 months after SBRT. Patients who underwent VATS were followed up as per National Comprehensive Cancer Network guidelines, with a CT scan every 4 to 6 months for 2 years and then annually thereafter.

Follow-up data were obtained by chart review and were available for all patients. Dates and type of recurrence were recorded, and the authors reviewed and concurred on classifications of all documented recurrences. Local recurrence was defined as progression of the primary tumor for the SBRT group and as recurrence at the ipsilateral lung staple lines in the VATS group. Regional recurrence was defined as tumor progression within the ipsilateral hilum or mediastinum. Distant recurrence was defined as failure outside of the thorax or in the contralateral lung or mediastinum. Incidences of second primary lung cancer were documented but were not considered recurrences for the purpose of this study. Definitions for second primary lung cancer and overall, recurrence-free, and lung-cancer-specific survival were as defined in previous literature. ${ }^{18-20}$

\section{Statistical Analysis}

Statistical analyses were performed with SAS, Version 9.1 and JMP, Version 13 (SAS Institute Inc, Cary, NC). $P<.05$ was considered the cutoff for significance, and all tests were 2 -sided. $P$ values were not adjusted for multiplicity. Differences in the distribution of preoperative characteristics were tested with chi-square analysis or the Fisher exact test for categoric variables and with the Wilcoxon 2-sample test for continuous variables.

Because the SBRT and VATS groups had different preoperative risk profiles, propensity matching was done, using a 1:1 greedy match algorithm without replacement. The type of procedure was the dependent variable in the logistic regression model used to create the propensity scores; the available independent predictors were CCI score, gender, clinical staging, forced expiratory volume in 1 second $\left(\mathrm{FEV}_{1}\right)$ predicted, age, and hypertension. All variables except age and clinical staging were significant in univariate analysis and therefore were used to compute propensity scores. Matching patients by these scores yielded 37 matched pairs. To determine whether the preoperative risk factors were well balanced, we calculated the standardized differences to compare preoperative characteristics between SBRT and VATS patients in the full cohort and in the propensity-matched patients. To compare outcomes between the propensity-matched patients, paired $t$ tests were used.

Time-to-event outcomes were analyzed by the Kaplan-Meier method, and the median follow-up time was calculated by the reverse Kaplan-Meier method. Patients who survived to the end of the study (May 20,2017) were considered censored at the time of the last follow-up when confirmed alive. For patients who died, their cases were censored upon death for survival analysis and at the time of the last negative imaging for recurrence analysis. Because we used propensity-matched data, the time-to-event comparisons between the SBRT and VATS groups used stratified log-rank $P$ values calculated by using the Cox regression stratified by matched pairs. The hazard ratios for survival and recurrence after SBRT versus VATS were obtained from a Cox proportional hazards regression model, with a robust sandwich estimator to account for the correlations between matched pairs that modeled time to event after the procedure, using type of procedure as the single independent variable. The assumption of proportional hazards over time between the 2 groups was verified both graphically with log-negative log survivor functions and numerically with the supremum test $P$ value.

To identify potential predictors of death and recurrence, 4 sets of multivariate analyses were conducted. First, we ran logistic regressions to model death or recurrence with stepwise selection for all patients $(n=183)$ by using these preoperative variables: SBRT versus VATS, gender, active smoking, hypertension, mediastinal staging with endobronchial ultrasonography, clinical staging, age, $\mathrm{FEV}_{1}$ predicted, $\mathrm{CCI}$ score (which includes COPD, previous cardiac disease [coronary artery disease, congestive heart failure, or myocardial infarction], and diabetes), tumor size, and pathologic cell type. Second, we used these same variables to run Cox proportional hazard models for the time to death or time to recurrence. Third, using the propensity-matched data, we ran conditional logistic regressions to model death or recurrence, with each matched pair as a stratum to consider the matched nature of the data. The independent predictors were a subset of the preoperative variables, because we could not use the variables used in the propensity match. These predictors were SBRT versus VATS, active smoking, mediastinal staging with endobronchial ultrasonography, clinical staging, age, tumor size, and pathologic cell type. Fourth, we used these same variables to run Cox proportional hazard models stratified by matched pairs for the time to death or time to recurrence. Inspecting the variance inflation factors confirmed that multicollinearity was not an issue.

\section{RESULTS}

The study cohort comprised 183 patients who underwent VATS $(\mathrm{n}=127)$ or SBRT $(\mathrm{n}=56)$. Compared with the VATS group, the SBRT group had a higher prevalence of several risk factors (Table 1). Tumor size and clinical stage distribution were similar between groups. After propensity matching, 37 matched pairs from each group had more comparable characteristics (Table 1), with appropriate standardized differences. Pretreatment invasive mediastinal staging with endobronchial ultrasonography was performed more often in SBRT cases $(69.6 \%)$ than in VATS cases $(31.5 \% ; P<.0001)$. This difference persisted despite the propensity match.

\section{Stereotactic Body Radiotherapy Treatment Details and Toxicity}

Table 2 shows the propensity-matched patients' results. Of the 37 matched patients who received SBRT, 26 (70.3\%) were deemed medically inoperable; the remaining 11 patients $(29.7 \%)$ refused surgery or sought primary SBRT as a preferable treatment. Thirty-two patients who received SBRT $(86.5 \%)$ had a complete response evident on post-treatment CT scan. There were no grade 4 or greater toxicities.

\section{Video-Assisted Thoracoscopic Lobectomy Treatment Details and Complications}

Of the 37 propensity-matched patients who received VATS, all had a complete (R0) resection with negative microscopic margins on final pathologic examination. Seven patients $(18.9 \%)$ who received VATS had pathologic upstaging. There was no operative, 30-day, or 90-day mortality. After VATS, 9 patients $(24.3 \%)$ had complications, none greater than grade 2. Most of the complications were pulmonary (Table 2).

\section{Survival}

Median follow-up was 3.7 years (SBRT) (95\% CI, 3.34.6) versus 3.6 years (VATS) (95\% CI, 3.1-4.6). During 
TABLE 1. Preoperative characteristics of all patients and propensity-matched patients

\begin{tabular}{|c|c|c|c|c|c|c|c|c|c|}
\hline \multirow[b]{2}{*}{ Variable } & \multicolumn{5}{|c|}{ All patients } & \multicolumn{4}{|c|}{ Propensity-matched patients } \\
\hline & $\begin{array}{c}\text { Overall } \\
(n=183)\end{array}$ & $\begin{array}{c}\text { SBRT } \\
(n=56)\end{array}$ & $\begin{array}{c}\text { VATS } \\
(n=127)\end{array}$ & $\begin{array}{c}\text { SBRT vs } \\
\text { VATS } \\
P \text { Value }\end{array}$ & $\begin{array}{l}\text { SBRT vs } \\
\text { VATS } S D\end{array}$ & $\begin{array}{l}\text { Overall } \\
(n=74)\end{array}$ & $\begin{array}{c}\text { SBRT } \\
(\mathbf{n}=\mathbf{3 7})\end{array}$ & $\begin{array}{c}\text { VATS } \\
(\mathbf{n}=\mathbf{3 7})\end{array}$ & $\begin{array}{l}\text { SBRT vs } \\
\text { VATS } S D\end{array}$ \\
\hline Age, y & $65(61-72)$ & $69.5(64-78)$ & $64(60-69)$ & $<.0001$ & 0.81 & $66(63-73)$ & $66(63-72)$ & $68(63-73)$ & -0.01 \\
\hline Male & $172(94.0)$ & $55(98.2)$ & $117(92.1)$ & .18 & 0.29 & $72(97.3)$ & $36(97.3)$ & $36(97.3)$ & 0.00 \\
\hline $\mathrm{FEV}_{1} \%$ predicted & $72(58-87)$ & $62(51-76)$ & $75.5(66-89)$ & .0005 & -0.54 & $68(51-83)$ & $68(47-81)$ & $68(56-84)$ & -0.18 \\
\hline Active smoker* & $87(47.5)$ & $30(53.6)$ & $57(44.9)$ & .28 & 0.17 & $40(54.1)$ & $21(56.8)$ & $19(51.4)$ & 0.11 \\
\hline Hypertension & $123(67.2)$ & $29(51.8)$ & $94(74.0)$ & .0032 & -0.47 & $46(62.2)$ & $23(62.2)$ & $23(62.2)$ & 0.00 \\
\hline $\begin{array}{l}\text { Clinical staging } \\
\text { IA } \\
\text { IB }\end{array}$ & $\begin{array}{r}136(74.3) \\
47(25.7)\end{array}$ & $\begin{array}{l}42(75.0) \\
14(25.0)\end{array}$ & $\begin{array}{l}94(74.0) \\
33(26.0)\end{array}$ & .89 & -0.45 & $\begin{array}{l}58(78.4) \\
16(21.6)\end{array}$ & $\begin{array}{r}28(75.7) \\
9(24.3)\end{array}$ & $\begin{array}{r}30(81.1) \\
7(18.9)\end{array}$ & 0.11 \\
\hline CCI score $>5$ & $68(37.2)$ & $37(66.1)$ & $31(24.4)$ & $<.0001$ & 1.14 & $37(50.0)$ & $19(51.4)$ & $18(48.7)$ & 0.05 \\
\hline Mediastinal staging via EBUS & $79(43.2)$ & $39(69.6)$ & $40(31.5)$ & $<.0001$ & 0.83 & $42(56.7)$ & $28(75.7)$ & $14(37.8)$ & 0.83 \\
\hline Tumor size, $\mathrm{cm}$ & $2.2(1.6-3.0)$ & $2.2(1.5-2.8)$ & $2.3(1.7-3.0)$ & .31 & -0.21 & $2.2(1.6-3.0)$ & $2.2(1.6-2.7)$ & $2.3(1.7-3.0)$ & -0.30 \\
\hline Pathologic cell type & & & & .012 & 0.52 & & & & 0.27 \\
\hline Adenocarcinoma & $106(57.9)$ & $24(42.9)$ & $82(64.6)$ & & & $32(43.2)$ & $17(46.0)$ & $15(40.5)$ & \\
\hline Adenosquamous & $9(4.9)$ & $2(3.6)$ & $7(5.5)$ & & & $4(5.4)$ & $1(2.7)$ & $3(8.1)$ & \\
\hline Squamous cell carcinoma & $56(30.6)$ & $23(41.1)$ & $33(26.0)$ & & & $31(41.9)$ & $15(40.5)$ & $16(43.2)$ & \\
\hline Other & $12(6.6)$ & $7(12.5)$ & $5(3.9)$ & & & $7(9.5)$ & $4(10.8)$ & $3(8.1)$ & \\
\hline
\end{tabular}

Data reported as $\mathrm{n}(\%)$ for categoric variables and median (IQR) for continuous variables. SBRT, Stereotactic body radiotherapy; VATS, video-assisted thoracoscopic lobectomy; $S D$, standardized difference; $F E V_{I}$, forced expiratory volume in 1 second; $C C I$, Charlson Comorbidity Index; EBUS, endobronchial ultrasonography. *Within 1 month of treatment.

follow-up, 24 patients died; 18 of $37(48.7 \%)$ patients who received SBRT and 6 of 37 patients $(16.2 \%)$ who received VATS $(P=.0007)$.

Overall survival was inferior with SBRT; median survival was 3.1 years (censored data) in this group, whereas most of those who received VATS survived to most recent follow-up (ie, median survival was $\geq 8$ y) $(P=.0016)$. The 1 -year overall, 3-year overall, and 3-year recurrence-free survivals (Figure 1) were $89.2 \%, 52.9 \%$, and $38.5 \%$ after SBRT and $94.6 \%, 85.7 \%$, and $82.8 \%$ after VATS $(P<.005$ for all $)$, respectively.

Lung cancer was the cause of death in 6 of 37 patients $(16.2 \%)$ who received SBRT and 2 of 37 patients $(5.4 \%)$ who received VATS $(P=.10)$. Lung cancer-specific survival (Figure 2) at 3 years was $78.1 \%$ (SBRT) versus $93.6 \%$ (VATS) $(P=.055)$.

\section{Recurrence}

The 3-year actuarial local control rate for the SBRT group was $92.5 \%$, compared with $100 \%$ for the VATS group $(P=.068)$. Actuarial rates of freedom from local, regional, and distant recurrence and from any recurrence are shown in Table 3.

Lung cancer recurred in 18 patients during follow-up (15/ 37 [40.5\%] SBRT vs 3/37 [8.1\%] VATS; $P=.0007$ ). Kaplan-Meier rates of freedom from any recurrence (actuarial tumor control) are shown in Figure 2. The 3-year actuarial tumor control rate was $54.3 \%$ after SBRT and $90.6 \%$ after VATS $(P=.0038)$. Most of the recurrences in both groups were regional (6/15 SBRT, 1/3 VATS) or distant (9/15 SBRT, 2/3 VATS), rather than local (2/15 SBRT, 0 VATS). One patient who received SBRT had local and regional recurrences that were diagnosed simultaneously, and 1 patient had both regional and distant recurrences. Second primary lung cancers developed in 5 patients (2 SBRT, 3 VATS) $(P=.66)$, but these were not considered recurrences for the purposes of this study.

\section{Multivariable Regression Analysis}

Multivariable regression analysis showed that SBRT treatment independently predicted both poorer overall survival and recurrence in the entire cohort (mortality odds ratio [OR], 9.8, $P<.0001$; recurrence $\mathrm{OR}, 4.26, P<.0001$ ) and in the propensity-matched patients (mortality OR, $11.6, P=.019$; recurrence $\mathrm{OR}, 9.9, P=.031)$. In addition, invasive mediastinal staging with endobronchial ultrasonography predicted greater survival (OR, $0.47, P=.015$ ) and, nonsignificantly, less recurrence (hazard ratio, 0.53 , $P=.08$ ) in the unmatched patients. None of the other variables independently predicted survival or recurrence.

\section{DISCUSSION}

Among veteran patients with clinical stage I lung cancer and many comorbidities, we found that VATS had better 
TABLE 2. Treatment variables in propensity-matched stereotactic body radiotherapy and video-assisted thoracoscopic lobectomy cases (n= 37 for each)

\begin{tabular}{|c|c|}
\hline Variable & Value \\
\hline \multicolumn{2}{|l|}{ SBRT cases } \\
\hline \multicolumn{2}{|l|}{ Reason for SBRT } \\
\hline Medically inoperable & $26(70.3)$ \\
\hline Patient preference & $11(29.7)$ \\
\hline Fiducial placement & $36(97.3)$ \\
\hline Tumor volume, $\mathrm{cm}^{3}$ & $6.1(2.4-12.3)$ \\
\hline Total dose, Gy & $56(50-56)$ \\
\hline No. of fractions & $4(4-5)$ \\
\hline Biologic effective dose, Gy & $134.4(100.0-134.4)$ \\
\hline \multicolumn{2}{|l|}{ Imaging $\mathrm{CT}$ result } \\
\hline Complete response & $32(86.5)$ \\
\hline Partial response & $2(5.4)$ \\
\hline Progression & $0(0.0)$ \\
\hline No change & $3(8.1)$ \\
\hline \multicolumn{2}{|l|}{ Mortality } \\
\hline $30-d$ & $0(0.0)$ \\
\hline $90-\mathrm{d}$ & $1(2.7)$ \\
\hline $180-d$ & $2(5.4)$ \\
\hline Any toxicity & $9(24.3)$ \\
\hline Late toxicity & $9(24.3)$ \\
\hline \multicolumn{2}{|l|}{ Late toxicity grade } \\
\hline Grade 1 & $5(55.6)$ \\
\hline Grade 2 & $2(22.2)$ \\
\hline Grade 3 & $2(22.2)$ \\
\hline \multicolumn{2}{|l|}{ Late toxicity type* } \\
\hline Pneumonitis & $3(33.3)$ \\
\hline Rib pain & $4(44.4)$ \\
\hline Pleural effusion & $1(11.1)$ \\
\hline Dyspnea & $1(11.1)$ \\
\hline Shortness of breath & $1(11.1)$ \\
\hline \multicolumn{2}{|l|}{ VATS cases } \\
\hline \multicolumn{2}{|l|}{ Mortality } \\
\hline $30-d$ & $0(0.0)$ \\
\hline $90-d$ & $0(0.0)$ \\
\hline $180-d$ & $1(2.7)$ \\
\hline Any complication & $9(24.3)$ \\
\hline \multicolumn{2}{|c|}{ Complication grade (by Dindo and colleagues ${ }^{26}$ ) } \\
\hline 1 & $3(33.3)$ \\
\hline 2 & $6(66.6)$ \\
\hline Postoperative events & $9(24.3)$ \\
\hline Pneumothorax & $3(33.3)$ \\
\hline Additional chest tube & $2(22.2)$ \\
\hline Atrial arrhythmia & $2(22.2)$ \\
\hline $\begin{array}{l}\text { Urinary retention/urinary tract } \\
\text { infection }\end{array}$ & $2(22.2)$ \\
\hline \multicolumn{2}{|l|}{ Resection status on pathology } \\
\hline R0 & $37(100.0)$ \\
\hline $\mathrm{R} 1$ & $0(0.0)$ \\
\hline $\begin{array}{l}\text { No. mediastinal lymph node } \\
\text { stations on pathology } \\
\text { examination }\end{array}$ & $3(2-4)$ \\
\hline
\end{tabular}

TABLE 2. Continued

\begin{tabular}{cl}
\hline \multicolumn{1}{c}{ Variable } & \multicolumn{1}{c}{ Value } \\
\hline Pathologic upstage & \\
Stage 1 to 2 & $5(13.5)$ \\
Stage 1 to 3 & $2(5.4)$ \\
\hline
\end{tabular}

Data reported as $\mathrm{n}(\%)$ for categoric variables and median (IQR) for continuous variables. SBRT, Stereotactic body radiotherapy; $C T$, computed tomography; VATS, video-assisted thoracoscopic lobectomy; $R O$, complete resection; $R 1$, microscopic positive margin. *One patient had both late grade 1 rib pain and pneumonitis.

outcomes than SBRT in terms of both disease control and survival. These results are similar to those of previous retrospective studies that compared medically inoperable patients treated with SBRT to operable patients treated with surgical resection, ${ }^{18}$ confirming that outcomes are similar in veterans with high rates of smoking and COPD.

Although SBRT is considered less invasive than surgery, both treatments were well tolerated in our study. Our patients had higher comorbidity index scores and higher rates of COPD and smoking than patients in other studies, yet the expected higher degree of toxicity with SBRT was not observed in our cohort. These outcomes are especially compelling when one considers evidence of worse outcomes with radiation in smokers with COPD, including poorer tumor control ${ }^{28}$ and greater toxicity, ${ }^{29}$ yet few studies have been published regarding outcomes for patients with COPD and NSCLC treated with definitive SBRT. ${ }^{30,31}$

These results show that modern SBRT techniques can be safe and effective in current smokers with COPD. Nonetheless, care must be taken in delivering high doses of radiation, because several studies have demonstrated severe toxicity when SBRT is used inappropriately, especially in treating central tumors. ${ }^{32}$ In our early experience with SBRT, we decided not to treat central tumors with it, which probably helped limit toxicity.

Local tumor control rates with SBRT in our study were comparable to those published in contemporary literature. $^{2-10}$ Our study adds to the growing body of evidence for the effectiveness of SBRT; 92.5\% 3-year actuarial freedom from local recurrence represents a noteworthy improvement over conventional radiation therapy. Regional and distant recurrence rates, overall recurrence rates, and cancer-specific survival for SBRT were similar to those reported in other studies. ${ }^{18}$

The local control rates in our study support using SBRT for medically inoperable stage I lung cancer in veterans. Despite the rapid increase in the use of SBRT ${ }^{33,34}$ and the growing evidence of its superiority over conventionally fractionated radiotherapy, ${ }^{8-10}$ SBRT has not yet become the dominant treatment modality for this indication in the United States. A recently published article revealed surprisingly low national use of SBRT for treating stage I 

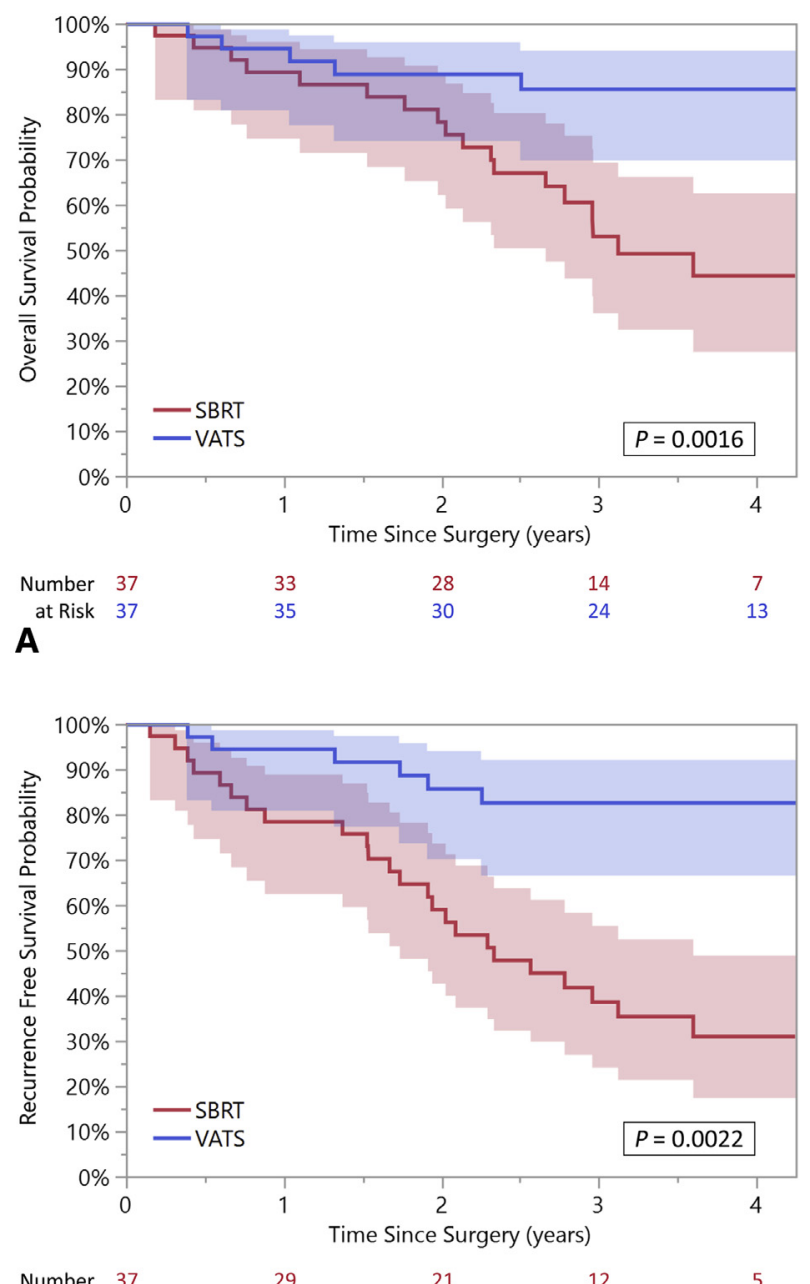

\begin{tabular}{lllll} 
at Risk 37 & 34 & 21 & 12 & 5 \\
\hline
\end{tabular}

B

FIGURE 1. Kaplan-Meier actuarial survival curves for (A) overall survival and (B) recurrence-free survival. SBRT, Stereotactic body radiotherapy; VATS, video-assisted thoracoscopic lobectomy.

NSCLC: Only $19 \%$ of surveyed US radiation oncologists reported using SBRT for their most recently treated medically inoperable patient with a peripheral lung tumor less than $5 \mathrm{~cm} .{ }^{35}$ Possible explanations for this underuse include limited SBRT capability, training, and access, as well as a lack of prospective randomized clinical trial data demonstrating efficacy. We hope our findings will increase the impetus to expand the use of SBRT and to conduct highquality clinical-effectiveness trials.

We attribute the significant differences between our study groups to careful patient selection. All of our patients were reviewed by a multidisciplinary tumor board for consensus on treatment recommendations. Our SBRT group, like those in many other studies, consisted of mostly medically inoperable patients with severe comorbidities and poor lung function, which accounts for their relatively low rates of overall and recurrence-free survival. In contrast, VATS
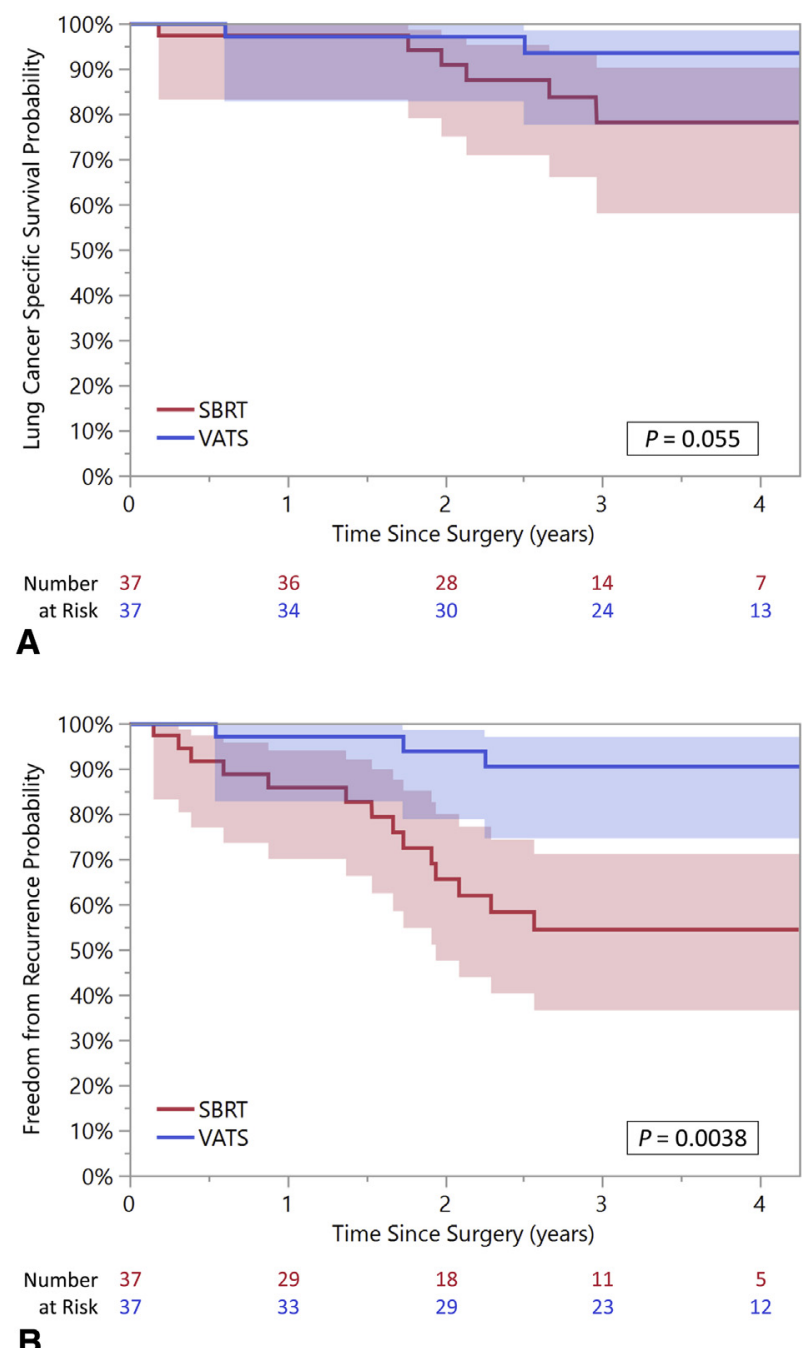

FIGURE 2. Kaplan-Meier actuarial log-rank curves for (A) lung cancerspecific survival (B) and freedom from any recurrence. SBRT, Stereotactic body radiotherapy; VATS, video-assisted thoracoscopic lobectomy.

resulted in excellent overall survival, recurrence-free survival, and cancer-specific survival-results that SBRT would have to match to be competitive in operable patients.

Significant risk factors were more prevalent in the mostly medically inoperable SBRT group in the overall cohort, but propensity matching produced comparable groups for the main outcome comparisons (Table 1). However, the VATS cohort was also high risk, having high rates of active smoking and COPD, a low mean $\mathrm{FEV}_{1}$, and a higher CCI score than patients in many other reported surgical series. We believe that the minimal invasiveness of VATS improves outcome in some higher-risk patients, such as ours, increasing high-risk patients' chances of tolerating major lung resection.

Despite good local tumor control with SBRT, better longterm outcomes with VATS may be related to more complete tumor staging. With an anatomic oncologic surgical 
TABLE 3. Actuarial survival and recurrence rates for 37 propensity-matched stereotactic body radiotherapy and video-assisted thoracoscopic lobectomy cases

\begin{tabular}{lccc}
\hline \multicolumn{1}{c}{ Variable } & SBRT \% (no. at risk) & VATS \% (no. at risk) & $P$ value* \\
\hline Freedom from local recurrence, 3 y & $92.5(12)$ & $100.0(24)$ & .068 \\
Freedom from regional recurrence, 3 y & $76.5(12)$ & $96.7(23)$ & .060 \\
Freedom from distant recurrence, 3 y & $73.8(13)$ & $93.9(24)$ & .032 \\
Lung cancer-specific survival, 3 y & $78.1(14)$ & $93.6(24)$ & .055 \\
Overall survival, 1 y & $89.2(33)$ & $94.6(35)$ & .0016 \\
Overall survival, 3 y & $52.9(14)$ & $85.7(24)$ & .0016 \\
Recurrence-free survival, 3 y & $38.5(12)$ & $82.8(23)$ & .0022 \\
Freedom from any recurrence, 3 y & $54.3(11)$ & $90.6(23)$ & .0038 \\
\hline
\end{tabular}

SBRT, Stereotactic body radiotherapy; VATS, video-assisted thoracoscopic lobectomy. $* P$ value comparison for entire Kaplan-Meier curves.

resection, not only the tumor but also a lobe of the lung and the hilar and mediastinal lymph nodes are all removed. Of note, we found that $18.9 \%$ of our VATS cases were clinically understaged, with unsuspected nodal disease found on final pathology examination. After the nodal disease was removed, these patients were offered the potential benefit of adjuvant treatment. Assuming that the SBRT group had a similar percentage of understaged patients, many patients in that group would not have had complete treatment for their cancer, and the 2 groups' long-term outcomes would be expected to differ. However, the potential effect of understaging in the SBRT group should have been mitigated, at least partly, by the increased use of pretreatment invasive mediastinal staging with endobronchial ultrasonography-guided transbronchial needle aspiration in that group. Indeed, invasive mediastinal staging was associated with greater survival and lower recurrence rates on multivariable analysis. These results should encourage use of invasive mediastinal staging for potential SBRT cases, when feasible.

\section{Study Limitations}

Our study's limitations include its retrospective design, with resultant selection bias between the groups; its relatively small, single-center patient cohort; and differences between the 2 groups in follow-up intensity, which could result in lead-time bias favoring the VATS group. However, the length of follow-up and degree of difference in recurrence rates suggest that the difference between treatment arms cannot be accounted for by lead-time bias alone.

Propensity matching and multivariable regression analysis were used to compensate for significant baseline differences between our 2 patient groups for an objective analysis of association between treatment and outcomes. Treatment with SBRT independently predicted worse survival and recurrence. This result contradicts the recent suggestion that SBRT and surgery have equivalent outcomes. We believe that accurately comparing SBRT with surgery in both high-risk and normal-risk operable patients will require a large, multicenter randomized trial.

We acknowledge that there are significant challenges in prospectively comparing surgical and nonsurgical treatment effectiveness in cancer research. Difficulty in enrolling patients in such clinical trials will remain a potential barrier to determining the efficacy of SBRT, especially in the treatment of otherwise healthy patients with lung cancer, for whom surgery has been the standard of care for decades. However, the rapidly growing use of SBRT suggests that it is being used often even in operable patients, despite the lack of evidence. We believe that current literature does not answer the question; therefore, there should be equipoise among radiation oncologists and surgeons to justify another attempt at a randomized trial. Radiation oncologists should remember that surgical techniques have improved with time, becoming less invasive and resulting in less morbidity and mortality, as shown here with VATS. They should also remember that SBRT has not been associated with the high long-term survival and cure rates that surgical resection has produced in large numbers of patients for decades; therefore, SBRT should not be used in operable patients outside of a clinical trial. Surgeons participating in randomized trials should remember the existing data showing excellent local control with SBRT, and if the patients enrolled are medically operable, then salvage surgery for locoregional recurrence is an option to help improve tumor control.

We endorse the funded CSP \#2005 clinical trial Veterans Affairs Lung resection Or Radiosurgery (VALOR), in which operable patients with clinical stage I lung cancer will be randomly assigned to undergo lobectomy surgery or SBRT. This trial will enroll normal-risk operable patients, which we believe is essential to establishing the comparative effectiveness of the 2 treatments for operable lung cancer.

\section{CONCLUSIONS}

Surgical outcomes were excellent with VATS at a Veterans Affairs medical center. We found that SBRT was safe 
and produced favorable local tumor control but was associated with worse overall recurrence and survival than VATS. To date, SBRT has not been shown to be a viable alternative to surgery in operable patients, and this question should be addressed in phase III randomized trials.

\section{Conflict of Interest Statement}

Authors have nothing to disclose with regard to commercial support.

Dr Lorraine Cornwell had full access to all of the data in the study and takes responsibility for the integrity of the data and the accuracy of the data analysis. Katherine Simpson, MS, performed the statistical analysis. Stephen N. Palmer, PhD, ELS, contributed to the editing of the article.

\section{References}

1. Boily G, Filion E, Rakovich G, Kopek N, Tremblay L, Samson B, et al. Stereotactic ablative radiation therapy for the treatment of early-stage non-small-cell lung cancer: CEPO review and recommendations. J Thorac Oncol. 2015;10: 872-82.

2. Timmerman R, Papiez L, McGarry R, Likes L, DesRosiers C, Frost S, et al Extracranial stereotactic radioablation: results of a phase I study in medically inoperable stage I non-small cell lung cancer. Chest. 2003;124:1946-55.

3. McGarry RC, Papiez L, Williams M, Whitford T, Timmerman RD. Stereotactic body radiation therapy of early-stage non-small-cell lung carcinoma: phase I study. Int J Radiat Oncol Biol Phys. 2005;63:1010-5.

4. Onishi H, Shirato H, Nagata Y, Hiraoka M, Fujino M, Gomi K, et al. Hypofractionated stereotactic radiotherapy (HypoFXSRT) for stage I non-small cell lung cancer: updated results of 257 patients in a Japanese multi-institutional study. J Thorac Oncol. 2007;2:S94-100.

5. Chang JY, Balter PA, Dong L, Yang Q, Liao Z, Jeter M, et al. Stereotactic body radiation therapy in centrally and superiorly located stage I or isolated recurrent non-small-cell lung cancer. Int J Radiat Oncol Biol Phys. 2008;72:967-71.

6. Hof H, Muenter M, Oetzel D, Hoess A, Debus J, Herfarth K. Stereotactic singledose radiotherapy (radiosurgery) of early stage nonsmall-cell lung cancer (NSCLC). Cancer. 2007;110:148-55.

7. Hara R, Itami J, Kondo T, Aruga T, Uno T, Sasano N, et al. Clinical outcomes of single-fraction stereotactic radiation therapy of lung tumors. Cancer. 2006;106: 1347-52.

8. Onishi H, Kuriyama K, Komiyama T, Tanaka S, Sano N, Marino K, et al. Clinical outcomes of stereotactic radiotherapy for stage I non-small cell lung cancer using a novel irradiation technique: patient self-controlled breath-hold and beam switching using a combination of linear accelerator and CT scanner. Lung Cancer. 2004; 45:45-55.

9. Iyengar P, Timmerman RD. Stereotactic ablative radiotherapy for non-small cell lung cancer: rationale and outcomes. J Natl Compr Canc Netw. 2012;10:1514-20.

10. Baumann P, Nyman J, Hoyer M, Wennberg B, Gagliardi G, Lax I, et al. Outcome in a prospective phase II trial of medically inoperable stage I non-small-cell lung cancer patients treated with stereotactic body radiotherapy. J Clin Oncol. 2009; 27:3290-6.

11. Chang JY, Liu H, Balter P, Komaki R, Liao Z, Welsh J, et al. Clinical outcome and predictors of survival and pneumonitis after stereotactic ablative radiotherapy for stage I non-small cell lung cancer. Radiat Oncol. 2012;7:152.

12. Lagerwaard FJ, Verstegen NE, Haasbeek CJ, Slotman BJ, Paul MA, Smit EF, et al. Outcomes of stereotactic ablative radiotherapy in patients with potentially operable stage I non-small cell lung cancer. Int J Radiat Oncol Biol Phys. 2012; $83: 348-53$.

13. Senan S, Paul MA, Lagerwaard FJ. Treatment of early-stage lung cancer detected by screening: surgery or stereotactic ablative radiotherapy? Lancet Oncol. 2013; 14:e270-4.

14. van den Berg LL, Klinkenberg TJ, Groen HJ, Widder J. Patterns of recurrence and survival after surgery or stereotactic radiotherapy for early stage NSCLC. J Thorac Oncol. 2015;10:826-31.

15. Moghanaki D, Karas T. Surgery versus SABR for NSCLC. Lancet Oncol. 2013; 14:e490-1.
16. Solda F, Lodge M, Ashley S, Whitington A, Goldstraw P, Brada M. Stereotactic radiotherapy (SABR) for the treatment of primary non-small cell lung cancer; systematic review and comparison with a surgical cohort. Radiother Oncol. 2013;109:1-7.

17. Zhang B, Zhu F, Ma X, Tian Y, Cao D, Luo S, et al. Matched-pair comparisons of stereotactic body radiotherapy (SBRT) versus surgery for the treatment of early stage non-small cell lung cancer: a systematic review and meta-analysis. Radiother Oncol. 2014;112:250-5.

18. Hamaji M, Chen F, Matsuo Y, Kawaguchi A, Morita S, Ueki N, et al. Videoassisted thoracoscopic lobectomy versus stereotactic radiotherapy for stage I lung cancer. Ann Thorac Surg. 2015;99:1122-9.

19. Lou F, Huang J, Sima CS, Dycoco J, Rusch V, Bach PB. Patterns of recurrence and second primary lung cancer in early-stage lung cancer survivors followed with routine computed tomography surveillance. J Thorac Cardiovasc Surg. 2013; 145:75-82.

20. Martini N, Bains MS, Burt ME, Zakowski MF, McCormack P, Rusch VW, et al. Incidence of local recurrence and second primary tumors in resected stage I lung cancer. J Thorac Cardiovasc Surg. 1995;109:120-9.

21. Chang JY, Senan S, Paul MA, Mehran RJ, Louie AV, Balter P, et al. Stereotactic ablative radiotherapy versus lobectomy for operable stage I non-small-cell lung cancer: a pooled analysis of two randomised trials. Lancet Oncol. 2015;16:630-7.

22. Hamaji M, Groth SS, Sugarbaker DJ, Burt BM. Surgery versus SABR for resectable non-small-cell lung cancer. Lancet Oncol. 2015;16:e372.

23. Treasure T, Rintoul RC, Macbeth F. SABR in early operable lung cancer: time for evidence. Lancet Oncol. 2015;16:597-8.

24. Sharafkhaneh A, Petersen NJ, Yu HJ, Dalal AA, Johnson ML, Hanania NA. Burden of COPD in a government health care system: a retrospective observational study using data from the US Veterans Affairs population. Int J Chron Obstruct Pulmon Dis. 2010;5:125-32.

25. Darnell K, Dwivedi AK, Weng Z, Panos RJ. Disproportionate utilization of healthcare resources among veterans with COPD: a retrospective analysis of factors associated with COPD healthcare cost. Cost Eff Resour Alloc. 2013;11:13.

26. Dindo D, Demartines N, Clavien PA. Classification of surgical complications: a new proposal with evaluation in a cohort of 6336 patients and results of a survey. Ann Surg. 2004;240:205-13.

27. Common Terminology Criteria for Adverse Events (CTCAE) version 4.03. U.S. Department of Health and Human Services, National Institutes of Health, National Cancer Institute. Available at: http://evs.nci.nih.gov/ftp1/CTCAE/ CTCAE_4.03_2010-06-14_QuickReference_5x7.pdf. Accessed April 18, 2016.

28. Browman GP, Wong G, Hodson I, Sathya J, Russell R, McAlpine L, et al. Influence of cigarette smoking on the efficacy of radiation therapy in head and neck cancer. N Engl J Med. 1993;328:159-63.

29. Des Rochers C, Dische S, Saunders MI. The problem of cigarette smoking in radiotherapy for cancer in the head and neck. Clin Oncol ( $R$ Coll Radiol). 1992;4:214-6.

30. Palma D, Lagerwaard F, Rodrigues G, Haasbeek C, Senan S. Curative treatment of Stage I non-small-cell lung cancer in patients with severe COPD: stereotactic radiotherapy outcomes and systematic review. Int J Radiat Oncol Biol Phys. 2012;82:1149-56.

31. Stephans KL, Djemil T, Reddy CA, Gajdos SM, Kolar M, Machuzak M, et al. Comprehensive analysis of pulmonary function test (PFT) changes after stereotactic body radiotherapy (SBRT) for stage I lung cancer in medically inoperable patients. J Thorac Oncol. 2009;4:838-44.

32. Senthi S, Haasbeek CJ, Slotman BJ, Senan S. Outcomes of stereotactic ablative radiotherapy for central lung tumours: a systematic review. Radiother Oncol. 2013;106:276-82.

33. Haque W, Szeja S, Tann A, Kalra S, Teh BS. Changes in treatment patterns and overall survival in patients with early-stage non-small cell lung cancer in the United States after the incorporation of stereotactic ablative radiation therapy: a population-based analysis. Am J Clin Oncol. January 14, 2016 [Epub ahead of print].

34. Pan H, Simpson DR, Mell LK, Mundt AJ, Lawson JD. A survey of stereotactic body radiotherapy use in the United States. Cancer. 2011;117:4566-72.

35. Kong FM, Cuneo KC, Wang L, Bonner JA, Gaspar LE, Komaki R, et al. Patterns of practice in radiation therapy for non-small cell lung cancer among members of the American Society for Radiation Oncology. Pract Radiat Oncol. 2014;4:e133-41.

Key Words: lung cancer, carcinoma, non-small cell, radiotherapy, SBRT, radiosurgery, stereotactic radiation, survival, recurrence, surgery, lobectomy, thoracoscopic lung resection 